\title{
Indeks van gepubliseerde artikels Jaargang 20-24
}

(Die uitgawe en bladsynommer volg na die titel van die bydrae)

\section{Jaargang 20}

Alberts, L. Die onstuitbare gang van die wetenskap: 1, 2.

De Kock, J.M., De Kock, J.C. De Villiers, C.G.S. Wetenskaplike en kultuurmens: 3-4, 117.

De Kock, K.N., Wolmarans, C.T., Strauss, H.D., Killian, M. Verspreiding en habitats van Lymnaea natalensis, tussengasheerslak van die lewerbot Fasciola gigantica, in Suid-Afrika: 2, 49.

De Villiers W. van Z. 'n Nuwe naam vir' 'n nuwe kernreaktor: 2, 54.

De Vos, G.P., Van Rensburg, B.W.J. Ontwerp- en konstruksieoorwegings vir ligte staalstrukture: 3-4, 101.

Gerber, A.M., Du Preez, P.H., Crous, A., Joubert, G. Serummelatonienkonsentrasies in koronêre hartvatsiektepasiënte met hipercholesterolemie: $1,22$.

Koorts, A.M., Hall, A.N, Viljoen, M. Lokalisering van intrasellulêre kalsium in die neutrofiel deur selektiewe presipitering met die antimonaatioon: $1,4$.

Lemmer H.H. Beraming van die kolfvermoë van Suid-Afrikaanse internasionale eendagkrieketspelers: 2, 45.

Maree, J.G., Basson, N.J.S., Malan, R. Optimalisering van leerbekwaamhede by graadnegeleerders: 'n Vergelyking van enkele vakdidaktiese meetinstrumente: $3-4,80$.

Reinecke, A.J. Die beroep op wetenskaplikheid in politieke, besigheids- en mediakringe: 3-4, 78.

Retief, F., Cilliers, L. Peulplante en siekte in die Grieks-Romeinse tyd: 1, 9.

Retief, F.P., Cilliers, L. Konsepte van oorerwing in Grieks-Romeinse tye: 3-4, 94.

Scheffer, C., Heyns, P.S. Masjiengereedskap-toestandmonitering en optimering van masjineringsprosesse - 'n oorsig: 2, 30.

Smits, D.P. Sal die Era van Aquarius met 'n "skrikkelsprong" in die millennium tot sy reg kom? : 1, 14

Van der Merwe, J.H. Epitaksie - Oriënteringskriterium: 304, 108.

Von Gruenewaldt, G. Wetenskap en die samelewing: besigheid soos gewoonlik, of nuwe eise vir 'n nuwe eeu? : $2,72$.

\section{Jaargang 21}

Bosch, F. Die groot skeiding: 3, 101 .

Broodryk, G.J., De Beer, W.H.J. Gerekenariseerde program vir inligtingsbestuur in die moderne waterlaboratorium: 2, 56.

De Kock, K.N., Wolmarans, C.T., Bornman, M., Maree, D.C. Verspreiding en habitats van Bulinus tropicus, tussengasheerslak van die peervormige bot Calicophoron microbothrium, in Suid-Afrika: 4, 114.

De Villiers, W. van Z. Is daar 'n behoefte aan Afrikaanse chemieterme? : 2, 75.

Herman, P.P.J. Die plantfamilie Asteraceae: 4. Interessante groeivorme en ekonomies belangrike soorte: 3, 108.

Hermann, P.P.J. Die plantfamilie Asteracea: 3. Die vrug: 1, 19

Kok, A.C., Kok, O.B. Dieetsamestelling van voëlsoorte op 'n binnelandse lughawe in Suid-Afrika: 1, 4.

Kok. A.C., Kok, O.B. Avifauna in grasveldgemeenskappe op enkele binnelandse lughawens in Suid-Afrika: 4, 140.

Kok. A.C., Kok, O.B. Prooimanipulasie in 'n grasveldgemeenskap op 'n binnelandse lughawe in Suid-Afrika: 4, 129.

Maree, J.G., Grimbeek, J. Toelating van graad 12-leerders met voorwaardelike of geen matrikulasie-endossement tot die Fakulteit Opvoedkunde: Universiteit van Pretoria: 3, 83.

Pienaar, W.J. Riglyne vir die keuse van ekonomiese openbare infrastruktuurprojekte: 2, 47.

Reinecke, A.J. Eienskappe van betroubare wetenskaplike inligting: 246.

Retief, F.P., Cilliers, J.F.G. Die eunug in die klassieke mitologie en samelewing: 4, 121.

Schoombie, S.W., Erasmus, M.H. Die evolusiespel: 'n eenvoudige algoritme vir die bepaling van 'n evolusionêr stabiele strategie: 4, 157.

Schoonwinkel, A., Milne, G.W., Du Plessis, J.J., Mostert, S. SUNSAT: Suid-Afrika se eerste satelliet in die ruimte: 3, 90.

Shaw, I.S. Analogieë tussen prosesse in fisiologie en ingenieurswese: 2, 60.

Swart, H., Van Dyk, S., Malan, S.F. In vitro evaluering van die effektiwiteit van vyf plante wat tradisioneel teen seksueel oordraagbare siektes gebruik word: 1,16

Verwoerd, D.W. Bek-en-klouseer: Ekonomiese oorwegings deurslaggewend by beheer: 1, 2.

Yadavalli, V.S.S., Bekker, A., Botha, M., Mostert, P.J. Berekening van a posteriori-verdeling in Bayes-analise: toepassing in 'n betroubaarheidstelsel wat afwisselend gebruik word: 3,78 .

\section{Jaargang 22}

Delport, D.J., Potgieter, J.H. Die ontwikkeling van 'n korrosiebestande langpadlengte-infrarooisel. Deel I: Konstruksieparameters en -oorwegings: 2-3, 89.

Donald, P.R., Sirgel, F.A., Venter, A., Fourie, P.B., Parkin, D.P., Seifart, H.I., Van de Wal, B.W., Maritz, J.S. 'n Oorsig van die bepaling van die vroeë bakterisidiese aktiwiteit van verskeie antituberkulosemiddels: 2-3, 79. 
Du Preez, C.C. Volhoubare landgebruik en grondkwaliteit: Organiese materiaal as indikator: 4, 106

Eloff, J.N., Swanepoel, A.C. Waarheen met Die Suid-Afrikaanse Tydskrif vir Natuurwetenskap en Tegnologie? : 2-3, 50.

Fick, M. Neurale netwerke as moontlike woordafkappingstegniek vir Afrikaans: 1, 2.

Groenewald, E.G., Van der Westhuizen, A.J. Enkele aspekte van die fisiologie van blomvorming by fotoperiodies sensitiewe plante: $1,6$.

Hauptfleisch,A.C., Meintjes, G.J. Gemeenskapsontwikkeling: die risiko's en geleenthede van deelname deur regstellende sakeondernemings in die Suid-Afrikaanse boubedryf: 1, 27.

Herman, P.P.J. Die plantfamilie Asteraceae: 5. Klassifikasie en die subfamilie Cichorioideae: 1, 45

Maree, J.G. There is a tide in the affairs of men ... Die uitdaging om werkbare en billike(-r) keuringsmeganismes te ontwerp: 1, 19.

Maree, J.G., Erasmus, C.P. 'n Analise van enkele veranderlikes wat die wiskundeprestasie van Tswanasprekende leerders beïnvloed: 2-3, 61.

Panzer, A., Viljoen, M. Die moeder as versteekte reguleerder: 4, 103.

Pienaar, W.J. Logistieke bestuur: die oorsprong, konseptuele ontwikkeling en betekenis daarvan as 'n hedendaagse studiegebied: 2-3, 52.

Pretorius, I.S. Die genetiese verbetering van wyndruifkultivars en wyngisrasse vir 'n markgerigte wynbedryf: Nuwe benaderings tot die oeroue kuns van wynbereiding: 1,31

Reinecke, J.A., Reinecke, S.A. Die beskerming van biologiese diversiteit deur gebruik te maak van die gevoeligheidsvariasie van spesies vir toksiese stowwe: 4,94 .

Retief, F., Cilliers, L. Fisionomie in die Grieks-Romeinse tyd : 1, 14.

Steyn, F. Die Statistiese Terminologieprojek en die web: 1, 44.

Zietsman, S. Endemiese tandfluorose geassosieerd met relatief lae fluoriedkonsentrasies in die Suid-Vrystaat, Suid-Afrika: 2-3, 69

\section{Jaargang 23}

Butler, H.J.B., Kok, O.B. Dieetsamestelling van vee-reiers (Bubulcus ibis) in die sentrale Vrystaat: 4, 90.

De Kock, K.N., Wolmarans, C.T. Verspreiding en habitats van Gyraulus connollyi, slaktussengasheer van ingewandsbotte van die familie Echinostomatidae, in Suid-Afrika: 3, 79.

Durand, J.F. Die ontdekking van 'n voorwerp naby Mapungubwe wat moontlik as 'n abakus gebruik was: 3, 46.

Erasmus, T. Engels-Afrikaans Oseanologiewoordeboek: 3, 87.

Fivaz, J., Cronjé, W.A. Genetiese algoritmes vir rekenaargesteunde induktor-onwerp: 3, 68.

Herman, P.P.J. Die plantfamilie Asteraceae: 6. Die subfamilie Asteroideae: 1-2, 35.

Maree, J.G., Louw, C.J., Millard, S. Die impak van tutoriale op die wiskundeprestasie van eerstejaarstudente: 1-2, 22.

Maree, J.G., Olivier, E., Swanepoel, A.C. Die 2004 senior Harmony Suid-Afrikaanse Wiskunde-olimpiade: 'n analise van die resultate van die senior groep, tweede rondte: 3,52 .

Nawaz, M.A., Kok, O.B. Aktiwiteitspatrone van bruinbere (Ursus arctos) op die Deosaiplato, noordelike Pakistan: 3, 61

Patterson, C., Smith, K.C., Van Wyk, L. Faktorringe van die Gauss-heelgetalle: 4, 114.

Potgieter, P.H. Die voorgeskiedenis van kwantumberekening: 1-2, 2.

Pretorius, R.W. Gehalteverbetering in hoër onderwys: 'n kritiese oorsig, met verwysing na Suid-Afrika: 4, 104.

Retief, F.P., Cilliers, L. Egiptiese geneeskunde: 4, 126.

Viljoen, M., Panzer, A., Koorts, A., Henn, P., Van den Bogaerde, J.B., Horn, E. Die effek van probiotika op die simptome en immunoglobulienvlakke van prikkelbare dermsindroom: 1-2, 22.

Viljoen, S., Hanekom, T., Cilliers, P.J. Oogknipbeheerde rekenaarmuis: ontwerp en evaluering: 1-2, 7.

Vorster, O.C., Halasz, L. Die gebruik van 'n reologiese tegniek in die bepaling van die verhardingsreaksiekinetika van 'n reaktiewe poliësterpoeierdeklaag: 1-2, 13.

Wolmarans, C.T., De Kock, K.N., Le Roux, J. Die gebruik van vraelyste en parasitologiese analises om laerisikogroepe vir bilharziasebesmetting, asook die faktore wat daartoe mag bydra, in 'n gemeenskap in 'n endemiese gebied in Suid-Afrika te identifiseer: 4,99 .

\section{Jaargang 24}

Aucamp, P.J. 'n Dekade van demokrasie: Omgewingsbestuur in 'n veranderende wêreld: 1-2, 21.

Eloff, J.N. Broodbome in Suid-Afrika - boekbespreking: 1-2, 48.

Kok, O.B. Vd M Louw, S., Kok, A.C. Snuitkewers in die dieet van die witvlerkkorhaan: meer as net voedsel? : 4, 118 .

Maree, J.G., Crafford, G. 'n Ondersoek na fasette van leerders in 'n privaat skool se studieoriëntasie en die verband daarvan met wiskundeprestasie: 3,84 .

Maree, J.G., Molepo, J.M., Owen, J.H., Ehlers, R. 'n Probleemgebaseerde benadering tot wiskunde in graad 9 en 11 in die Limpopo-provinsie: 4, 124.

Olivier, J., De Jager, A. 'n Etnobotaniese opname van Athrixia phylicoides en sy gebruike: 4,139

Pienaar, W.J. Die beraming van verhoogde streeksinkome wat uit ekonomies geregverdigde padbouprojekte spruit: 4, 108.

Potgieter, P.H., Heidema, J., Fouché, W.L. Kwantumberekening: 3, 60.

Reinecke, S.A. Ou en nuwe tendense in die ekotoksikologie: die relevansie van stresekologie en ekotoksikogenomika: 3, 52.

Van der Laan, J., Vorster, O.C. Hidrotalsiet, vervaardig uit magnesieterts, as niegiftige hittestabiliseerder vir polivinielchloried: 1$2,17$.

Viljoen, M., Johannsen, E., Panzer, A. Probiotika: dieet-aanvullende preparate van lewende, niepatogene mikroörganismes: 1-2, 2.

Viljoen, M., Koorts, A. Prebiotika: selektiewe substraat vir voordelige mikroflora: 1-2, 11.

Vorster. O.C. Die gebruik van parallelplaatreologie vir die bepaling van die intrinsieke viskositeit van poli-etileentereftalaat: 4,134 . 